\title{
Biochemical Mediators of Meningeal Inflammatory Response to Group B Streptococcus in the Newborn Piglet Model
}

\author{
EMILY W. Y. LING, FRANCISCO J. D. NOYA, GINETTE RICARD, KAE BEHARRY, \\ ELAINE L. MILLS, AND JACOB V. ARANDA
}

Department of Pediatrics [E.W.Y.L], University of British Columbia, B.C.'s Children's Hospital, Vancouver, Department of Pediatrics [F.J.D.N., E.L.M., J.V.A], McGill University, and Division of Neonatal Research [G.R., K.B.], Lady Davis Institute for Medical Research, Montreal, Canada \begin{abstract}
ThST
Theningeal inflammatory response to a heat-killed mutant
unencapsulated strain of type III group B Streptococcus (GBS) was studied in a newborn piglet model. GBS $\left(10^{9}\right.$ colonyforming unit equivalents) or saline (control) was inoculated intraventricularly. Serial cerebrospinal fluid measurements were done at baseline and over the course of the next $24 \mathrm{~h}$ for cytochemical changes and production of tumor necrosis factor (TNF) and prostaglandins. In separate experiments, we defined the time course of early changes during the first $6 \mathrm{~h}$ and dose response relationship over a range of inocula $10^{6}$ to $10^{9}$ colonyforming unit equivalents. The intraventricular inoculation of the heat-killed unencapsulated GBS induced marked leukocytosis and increased protein by $6 \mathrm{~h}$. These changes were preceded by a several hundredfold increase in TNF (maximum at $2 \mathrm{~h}$ ) and prostaglandins (maximum at 2-4 h). The early and sharp rise in TNF suggests its pivotal role in initiating the inflammatory cascade. The magnitude of the inflammatory response increased with increasing bacterial dose over the range studied. To study
\end{abstract}

the effect of encapsulation of GBS in the induction of meningeal inflammation, we compared the response to the unencapsulated mutant strain with that to the encapsulated parent strain. The encapsulated strain produced much smaller inflammatory changes, and only with high doses of bacteria. The GBS cell wall appeared to be the primary bacterial product triggering inflammation. Intraventricular injection of the heat-killed unencapsulated GBS with exposed cell wall can serve as a valid model for studying neonatal meningitis. (Pediatr Res 38: 981-987, 1995)
CFU, colony-forming units
CSF, cerebrospinal fluid
GBS, group B Streptococcus
PG, prostaglandin
TX, thromboxane
TNF, tumor necrosis factor
WBC, white blood cell

Neonatal meningitis continues to be associated with high mortality and morbidity despite effective antibiotic therapy and advanced intensive care technology. The current incidence is $0.4-1.0 / 1000$ live births $(1,2)$, and current mortality is $20-$ $40 \%$ with long-term neurologic sequelae in as many as onethird of the survivors (3). Over the past few years, studies on meningitis in human and in animal models have increased our understanding of the pathogenesis of infection and pathophysiology. It has been shown that bacterial products initiate a chain of inflammatory reactions with the formation of inflammatory cytokines and biochemical mediators (4-7). These events result in injury to the vascular lining of the brain and alteration in the CSF dynamics, brain metabolism, and the control of cerebral blood flow. Most animal models of bacterial

Received December 9, 1994; accepted June 13, 1995.

Correspondence and reprint requests: Emily W. Y. Ling, M.D., B.C.'s Children's Hospital, 4480 Oak Street, Vancouver, B.C., Canada V6H 3V4.

Supported by Medical Research Council Grant MA-12082. meningitis use adult animals. It is important to develop a neonatal animal model to study the pathophysiologic consequences of meningeal inflammation on the immature brain. It is the objective of this study to develop an animal model of neonatal meningitis using a common neonatal pathogen. GBS is a common causative organism of neonatal sepsis and GBS type III, in particular, is a common cause of neonatal meningitis (8).

In Gram-positive organisms, the techoic acid-containing cell wall has been suggested to be responsible for the initiation of inflammation. In an adult rabbit model, Tuomanen et al. (9) reported that CSF inflammatory changes could be induced by cisternal instillation of whole heat-killed unencapsulated strains of Pneumococcus or their isolated cell walls and concluded that the bacterial cell wall is the most potent pneumococcal surface component in inducing meningeal inflammation. Täuber et al. (10) demonstrated that the pneumococcal cell wall not only induced CSF cytochemical abnormalities but 
also pathophysiologic alterations similar to true meningeal infection. Whether the GBS cell wall would elicit cellular response and biochemical events in the CSF similar to those observed with pneumococcal cell wall has not been clearly established. McKnight et al. (11), using a cranial window preparation, demonstrated that both live and heat-killed GBS caused progressive dilatation of pial cerebral arterioles. This finding indicated that the GBS cell wall was highly active within the CNS, and the pathophysiologic effect on cerebral vasculature was thought to be mediated by oxygen radicals.

The specific objective of our study was to examine the inflammatory potential of GBS cell wall in a newborn piglet model. A series of experiments were carried out with specific objectives: 1) to examine the CSF cellular and biochemical response to intraventricular inoculation of a heat-killed preparation of a mutant unencapsulated strain of type III (as a source of exposed cell wall) or saline (control);2) to examine the time course of the CSF cytochemical and inflammatory mediator response to the heat-killed unencapsulated GBS; 3) to examine the dose response relationship of the inflammatory mediator response to different doses of heat-killed unencapsulated GBS; 4) to examine the effect of encapsulation of GBS on the induction of meningeal inflammation by comparing the response to intraventricular inoculation of two different strains of heat-killed type III GBS, an unencapsulated mutant strain and the encapsulated parent strain.

\section{METHODS}

\section{Experimental Animals}

Newborn Yorkshire piglets less than $5 \mathrm{~d}$ old were assigned to study and control groups. The study animals were given a 0.5 -mL inoculum of heat-killed GBS suspended in pyrogenfree saline by intraventricular inoculation. The method for intraventricular inoculation was developed and validated in previous experiments (12) and achieved by using a 24-gauge needle introduced through the parietal bone into one lateral ventricle to a depth of $13 \mathrm{~mm}$. The most satisfactory point of entry into the brain was approximately $2 \mathrm{~mm}$ caudal to the coronal suture and $4 \mathrm{~mm}$ lateral to the sagittal suture. The control animals received $0.5 \mathrm{~mL}$ of sterile normal saline in a similar manner. Serial CSF samples were obtained by cisterna magna puncture and examined for cytochemical changes and changes in inflammatory mediators. The animals were given brief inhalation anesthesia using nitrous oxide 70\%-oxygen $30 \%$ for the procedures of intraventricular injections and cisternal punctures. At the end of the experiment, the animal was killed, the inoculation into the ventricle was confirmed, and the brain was fixed in formalin for histologic examination. The study was approved by the Animal Care Committee of McGill University.

\section{Heat-Killed GBS Preparations}

Two different strains of GBS were used: a mutant unencapsulated strain of type III GBS (COH 1-13, kindly provided by C. E. Rubens, M.D., Ph.D., University of Washington, Seattle), with a specific defect in the production of the capsule (the heat-killed preparation of this served as a source of the GBS exposed cell wall) (13), and the encapsulated parent strain (COH-1) obtained from a clinical isolate, the cell wall of which was not exposed (14). The GBS strains were stored at $-70^{\circ} \mathrm{C}$ in Todd-Hewitt broth. To make the heat-killed preparation, an aliquot of the stock GBS was subcultured on a blood agar plate overnight and then grown to mid-logarithmic phase on ToddHewitt broth. The heat-killing of GBS was achieved by heating the mid-logarithmic phase grown GBS in a water bath at $60^{\circ} \mathrm{C}$ for $60 \mathrm{~min}$. The bacterial pellet was then washed three times and resuspended in sterile pyrogen-free sterile PBS at a concentration of $2 \times 10^{9} \mathrm{CFU}$ equivalents $/ \mathrm{mL}$. A batch of aliquots was prepared and frozen for storage at $-70^{\circ} \mathrm{C}$. The thawed inoculum was diluted to deliver different concentrations. The preparations tested negative for endotoxin (by amebocyte lysate assay, E-Toxate, supplied by Sigma Chemical Co. Diagnostics). They were also cultured to confirm killing of the bacteria.

\section{Measurements in CSF}

CSF was examined for WBC counts, protein, and glucose concentrations according to standard methods in the clinical laboratory. Assays for the cytokine, TNF, and for the PG inflammatory mediators were performed. Swine TNF was measured using an ELISA method, described by Gibson et al. (15, 16), with a "sandwich" TNF ELISA kit, developed and provided by Genentech Inc. PG production was examined by the assay of the following PG or stable PG metabolites: $\mathrm{PGE}_{2}$, $\mathrm{PGF}_{2 \alpha}$, 6-keto-PGF ${ }_{1 \alpha}$ (a stable metabolite of prostacyclin, $\mathrm{PGI}_{2}$ ), and $\mathrm{TXB}_{2}$ (a metabolite of $\mathrm{TXA}_{2}$ ), by RIA, using commercially available kits (Cedarlane Laboratories). CSF was also cultured at the beginning and the end of the experiment to confirm sterile meningitis.

\section{Experimental Protocol}

To achieve our specific objectives, four sets of experiments were conducted on different groups of animals:

CSF cellular and biochemical response to intraventricular inoculation of heat-killed unencapsulated GBS (exposed cell wall). Study animals $(n=7)$ were given $10^{9} \mathrm{CFU}$ equivalents of heat-killed unencapsulated GBS suspended in $0.5 \mathrm{~mL}$ of pyrogen-free saline by intraventricular inoculation. Control animals $(n=6)$ were given the same volume of normal saline. CSF was serially obtained by cisterna punctures at 0 (baseline), 6 , and $24 \mathrm{~h}$ after intraventricular inoculation and examined for cytochemical changes.

Time course of the cellular and biochemical changes to GBS exposed cell wall. In another group of study animals $(n=$ 7) given heat-killed unencapsulated GBS $\left(10^{9} \mathrm{CFU}\right.$ equivalents) and control animals $(n=6)$ given saline intraventricularly, serial CSF samples were obtained at 2-h intervals between 0 (baseline) and $6 \mathrm{~h}$. The magnitude of the inflammatory changes and the time to maximum response were recorded.

Dose response relationship of the inflammatory mediators to different doses of the heat-killed unencapsulated GBS. This was tested in 12 newborn piglets divided into groups of 2-3 each given heat-killed unencapsulated GBS into the ventricle at 
a dose of 0 (control-saline), $10^{6}, 10^{7}, 10^{8}$, or $10^{9} \mathrm{CFU}$ equivalents in $0.5 \mathrm{~mL}$ of saline. CSF was collected at $0,2,4$, and 6 h for the assay of TNF and PG concentrations.

Effect of encapsulation on the induction of meningeal inflammation. This was tested in a group of 12 newborn piglets divided into groups of 2-3 each given heat-killed encapsulated GBS into the ventricle at a dose of 0 (control), $10^{6}, 10^{7}, 10^{8}$, or $10^{9} \mathrm{CFU}$ equivalents in $0.5 \mathrm{~mL}$ of saline. Assay of the CSF for TNF and PG was performed at 0, 2, 4, and $6 \mathrm{~h}$. The results were compared with those obtained with the unencapsulated mutant strain given at the same doses.

\section{Data Analysis}

Nonparametric tests used were the Mann-Whitney test for comparison between study and control groups and the Wilcoxon test to detect changes from the baseline.

\section{RESULTS}

Heat-killed unencapsulated GBS induces marked CSF inflammatory changes. Table 1 shows the CSF cellular and biochemical response to the heat-killed unencapsulated GBS (study) or saline (control) given into the cerebral ventricle. At baseline $(0 \mathrm{~h})$, the CSF concentrations of WBC, protein, glucose, TNF, and $\mathrm{PGE}_{2}$ were not different between the control and the study group. In the control animals, no cellular or biochemical changes were observed over the time course of the experiment (Wilcoxon test). In contrast, the heat-killed unencapsulated GBS ( $10^{9} \mathrm{CFU}$ equivalents) in the study animals induced a marked inflammatory meningeal response by $6 \mathrm{~h}$. As shown in Table 1, the WBC counts and protein in the CSF increased markedly at $6 \mathrm{~h}$ and remained elevated at $24 \mathrm{~h}$ postinoculation. The CSF glucose concentrations did not change. This was expected because killed bacteria were used, and this finding was similarly shown by Tuomanen et al. (9) with heat-killed Pneumococcus. The concentrations of the

Table 1. CSF cellular and biochemical changes to intraventricular inoculation of saline (control) or the heat-killed unencapsulated $G B S$ (study) in newborn piglets

\begin{tabular}{lrccc}
\hline & $\begin{array}{c}\text { Time } \\
(\mathrm{h})\end{array}$ & $\begin{array}{c}\text { Control Saline } \\
(n=6)\end{array}$ & $\begin{array}{c}\text { Study GBS } 10^{9} \\
(n=7)\end{array}$ & $p$ value \\
\hline WBC (per mm $\left.)^{3}\right)$ & 0 & $3 \pm 0.8$ & $6 \pm 2.9$ & NS \\
& 6 & $147 \pm 56$ & $11743 \pm 4865^{*}$ & $p<0.005$ \\
& 24 & $33 \pm 15$ & $11301 \pm 4545^{*}$ & $p<0.05$ \\
Protein (g/L) & 0 & $0.4 \pm 0.02$ & $0.4 \pm 0.04$ & $\mathrm{NS}$ \\
& 6 & $0.9 \pm 0.3$ & $4.5 \pm 1.0^{*}$ & $p<0.05$ \\
& 24 & $1.1 \pm 0.3$ & $3.2 \pm 0.39^{*}$ & $p<0.05$ \\
Glucose (mmol/L) & 0 & $5.5 \pm 0.7$ & $6.1 \pm 0.9$ & $\mathrm{NS}$ \\
& 6 & $6.9 \pm 1.6$ & $5.4 \pm 1.6$ & $\mathrm{NS}$ \\
& 24 & $7.0 \pm 1.9$ & $6.5 \pm 1.9$ & $\mathrm{NS}$ \\
TNF (ng/ml) & 0 & $0.6 \pm 0.3$ & $1.0 \pm 0.5$ & $\mathrm{NS}$ \\
& 6 & $0.3 \pm 0.2$ & $43.0 \pm 11.6^{*}$ & $p<0.05$ \\
& 24 & $1.2 \pm 0.8$ & $1.3 \pm 0.4$ & $\mathrm{NS}$ \\
PGE $_{2}(\mathrm{pg} / 0.1 \mathrm{ml})$ & 0 & $44.7 \pm 24.3$ & $15.6 \pm 15.6$ & $\mathrm{NS}$ \\
& 6 & $21.6 \pm 10.6$ & $43.4 \pm 37.3$ & $\mathrm{NS}$ \\
& 24 & $0 \pm 0$ & $68.5 \pm 13.8$ & $p<0.05$ \\
\hline
\end{tabular}

Values are expressed as mean \pm SEM. The Mann-Whitney nonparametric test was used to compare between control and study group. The Wilcoxon test for repeated measures was used to detect changes from baseline $\left({ }^{*} p<0.05\right)$. proinflammatory mediators in the CSF also increased significantly in the study group. The TNF levels increased by 40 -fold at $6 \mathrm{~h}$. By $24 \mathrm{~h}$, the TNF levels had returned to almost baseline, probably because it can no longer be measured by standard TNF methodology at $24 \mathrm{~h}$ unless TNF receptors are measured, which should remain high. The $\mathrm{PGE}_{2}$ levels showed a trend to increase at 6 and $24 \mathrm{~h}$. When compared with the control animals (Mann-Whitney test), the study animals had a significantly higher levels of WBC and protein at both 6 and $24 \mathrm{~h}$, of TNF at $6 \mathrm{~h}$, and of $\mathrm{PGE}_{2}$ at $24 \mathrm{~h}$. The CSF cultures at the beginning and end of the experiment were all negative, confirming sterile meningitis. After the animals were killed at the end of the experiment, histologic examination of the brain under light microscopy showed significant meningeal inflammatory changes in the study group only. Infiltration with WBC was limited to the meninges, primarily at the basal areas. No inflammatory changes were seen in the ventricles, possibly because the inoculum of heat-killed bacteria drained rapidly to the subarachnoid space where it exerted its maximum inflammatory effect.

Time course of meningeal inflammation induced by GBS. Since the major cytochemical and proinflammatory mediator changes were well established by $6 \mathrm{~h}$, we next examined the early inflammatory changes in the first $6 \mathrm{~h}$ by obtaining CSF at $0,2,4$, and $6 \mathrm{~h}$ after inoculation of the GBS. It was not possible to obtain atraumatic cisterna punctures at all the scheduled times on all the animals. A median of five samples were available for each specified time. Figure 1 summarizes the major cytochemical and biochemical mediator changes in the $24 \mathrm{~h}$ postinoculation. In the study group, the marked leukocytosis and protein increase did not start until about $4 \mathrm{~h}$, peaked at $6 \mathrm{~h}$, and remained elevated at $24 \mathrm{~h}$. The TNF was the first inflammatory mediator to increase, from around $1 \mathrm{ng} / \mathrm{mL}$ at baseline to a maximum of above $200 \mathrm{ng} / \mathrm{mL}$ at $2 \mathrm{~h}$. Although still significantly increased at $6 \mathrm{~h}$ (but much lower than the maximum), the TNF concentrations had returned to baseline by $24 \mathrm{~h}$. The CSF glucose concentration did not change in either the control or the study group. Figure 2 shows that the increase in PG in the GBS group followed that of TNF, starting at $2 \mathrm{~h}$ and reaching a maximum at $4 \mathrm{~h}$. There was an increase in all the PG and PG metabolites measured, up to several hundredfold in the case of $\mathrm{PGE}_{2}, \mathrm{PGF}_{2 \alpha}$, and 6-keto-PGF $1 \alpha$ and about 10 -fold for $\mathrm{TXB}_{2}$. Similar to that found with TNF, the PG levels returned to baseline by $24 \mathrm{~h}$.

Dose response relationship between meningeal inflammation and GBS. There was a graded response in all the inflammatory parameters with increasing bacterial doses of the heatkilled unencapsulated GBS $\left(10^{6}-10^{9} \mathrm{CFU}\right.$ equivalents). Figure 3 illustrates the dose response relationship of the inflammatory mediator response to different doses of the heat-killed GBS. There was a sharp rise in the TNF concentrations at $2 \mathrm{~h}$ postinoculation, and the magnitude of response increases with increasing doses of GBS inocula over the range studied. The rise in 6-keto- $\mathrm{PGF}_{1 \alpha}$ concentrations was shown to illustrate the changes in PG concentrations. At higher bacterial doses $\left(10^{7}\right.$ and above), the peak increase in concentrations was either much larger or occurred earlier (at 2-4 h). At a lower dose $\left(10^{6}\right)$, the response was much smaller and occurred later (at 6 
WBC (Thousands/cu.mm.)

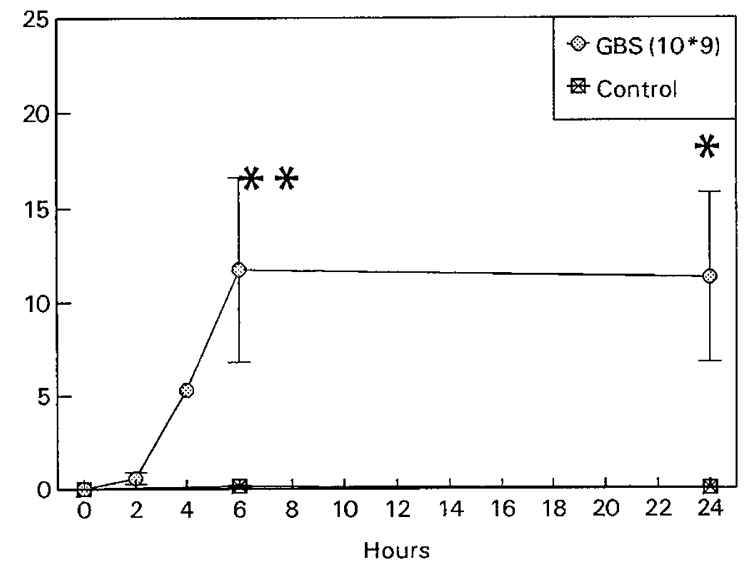

Protein $(g / L)$

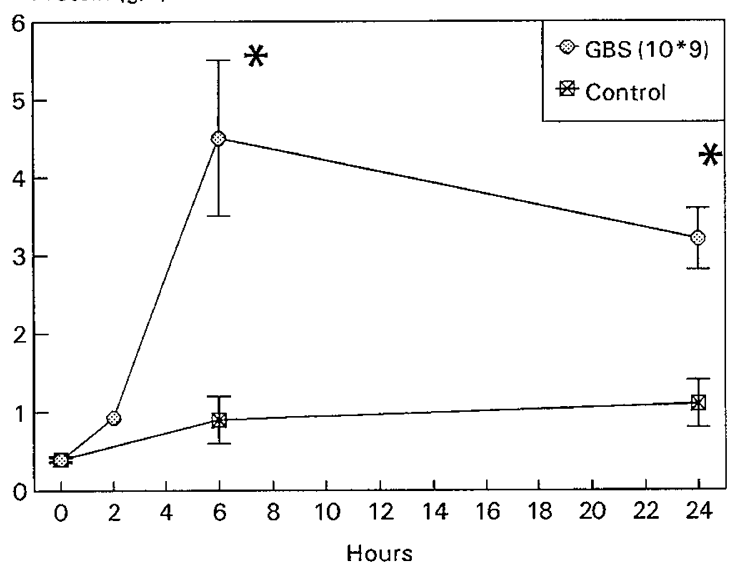

Glucose (mmol/L)
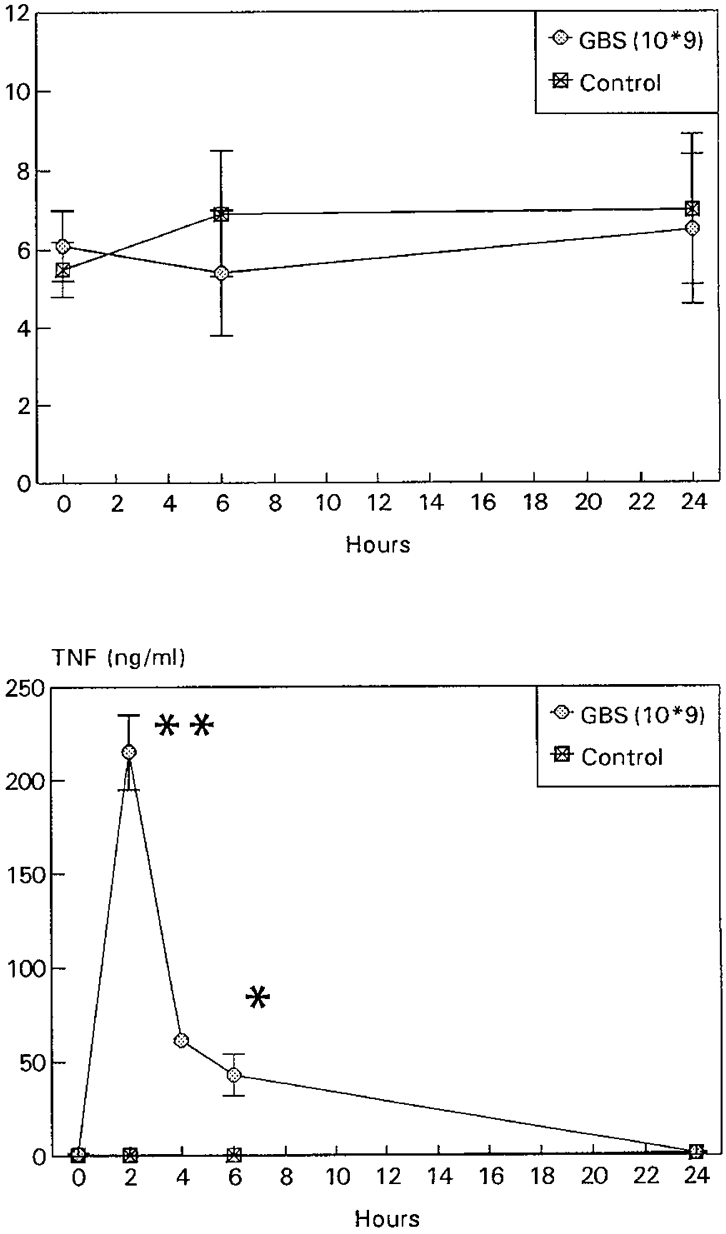

Figure 1. The CSF cellular and biochemical response to intraventricular inoculation of heat-killed unencapsulated GBS ( $10^{9}$ in $0.5 \mathrm{~mL}$ ) and saline (control). Values shown are mean \pm SEM. $* p<0.05$ between GBS and control group; $* * p<0.005$ between GBS and control group

CONTROL ( 0 -saline)

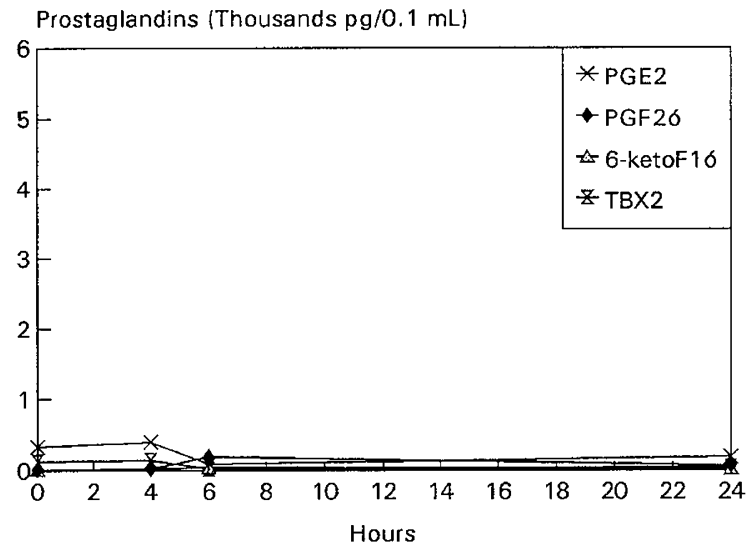

UNENCAPSULATED GBS $(10 * 9)$

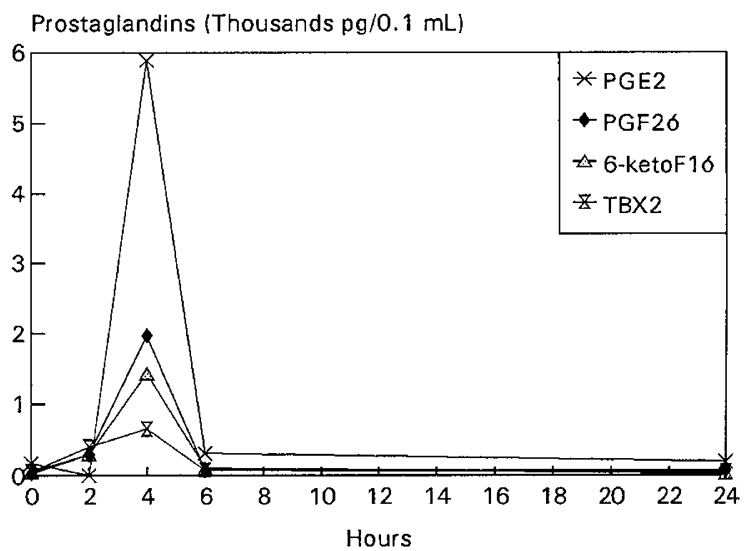

Figure 2. The CSF PG response to intraventricular inoculation of GBS exposed cell wall ( $10^{9}$ in $\left.0.5 \mathrm{~mL}\right)$ and saline (control). Mean values are shown. The mean peak concentration (and range) in $\mathrm{pg} / 0.1 \mathrm{~mL}$ at $4 \mathrm{~h}$ for the different PG were for $\mathrm{PGE}_{2}, 5891(796-17932) ; \mathrm{PGF}_{2 \alpha}, 1969(336-3961) ; 6-\mathrm{keto} \mathrm{PGF}_{1 \alpha}, 1431$ (139-3505); and $\mathrm{TXB}_{2} ; 649$ (339-1594).

h). The other $\mathrm{PG}, \mathrm{PGE}_{2}, \mathrm{PGF}_{2 \alpha}$, and $\mathrm{TXB}_{2}$, showed a similar pattern with not only a positive relation between the magnitude of response and the bacterial dose, but also an inverse relationship between the time to peak response and the bacterial dose. The leukocytosis and CSF protein showed a similar graded response, but the peak increase always occurred later at $6 \mathrm{~h}$ (results not shown), a few hours after the upsurge in the inflammatory mediators.

Effect of encapsulation of GBS in the induction of meningeal inflammation. Figure 4 summarizes the inflammatory 

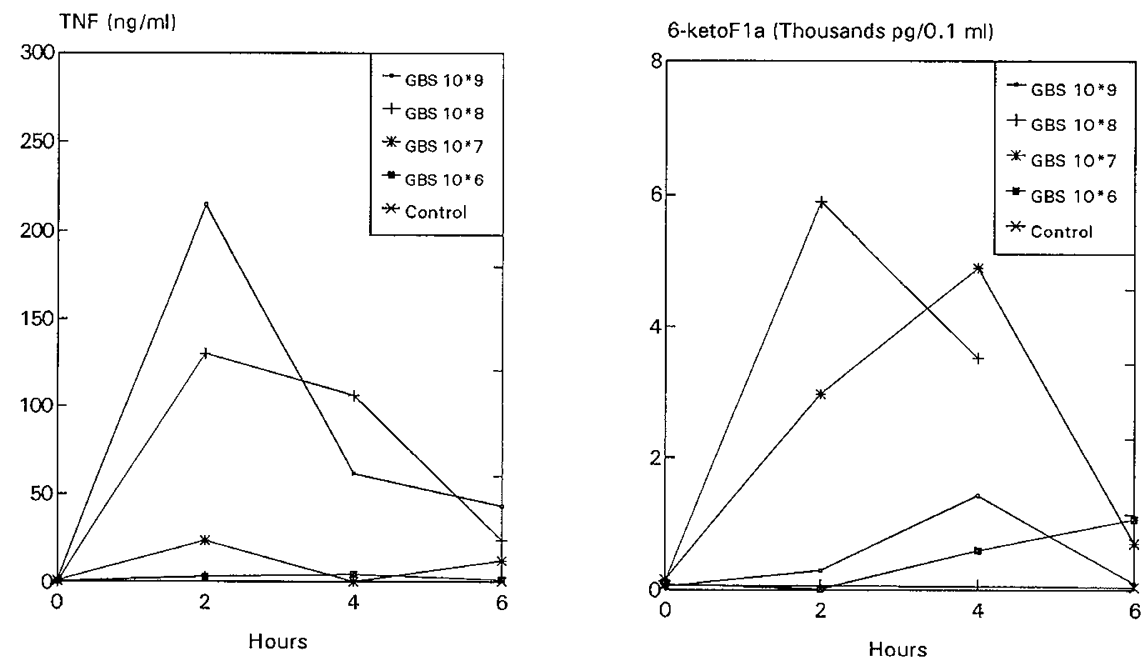

Figure 3. The CSF TNF and 6-keto-PGF ${ }_{1 \alpha}$ concentrations in response to different doses of heat-killed unencapsulated GBS $\left(0\right.$, saline; $10^{6}, 10^{7}, 10^{8}$, and $10^{9}$ CFU equivalents). Mean values are shown. The mean peak TNF concentration (and range) for different bacterial doses were: 109 $215(186-245) ; 10^{8}, 130$ $(62-211) ; 10^{7}, 24$; and $10^{6}, 3(0-4)$. The corresponding mean peak 6-keto-PGF ${ }_{1 \alpha}$ (and range) were: $10^{9}, 1431(139-3501) ; 10^{8}, 5898(3671-8125) ; 10^{7}, 4907$; and $10^{6}, 1075(43-2108)$.
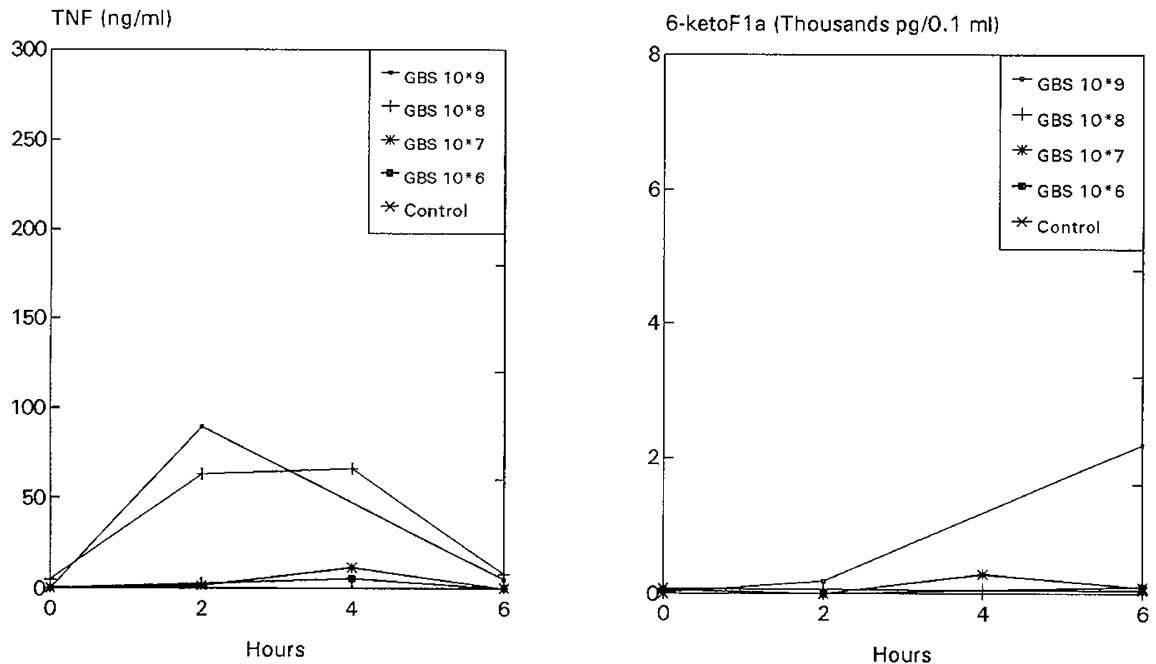

Figure 4. The CSF TNF and 6-keto-PGF ${ }_{1 \alpha}$ concentrations in response to different doses of a heat-killed encapsulated GBS $\left(10^{6}-10^{9}\right)$. Mean values are shown. The mean peak TNF concentration (and range) for different bacterial doses were: $10^{9}, 89 ; 10^{8}, 66(52-75) ; 10^{7}, 12(0-23) ;$ and $10^{6}, 5.6(0-12)$. The corresponding mean peak 6-keto-PGF $1 \alpha$ were: $10^{9}, 2188 ; 10^{8}, 0 ; 10^{7}, 285(137-295)$; and $10^{6}, 99$.

mediator response when the heat-killed encapsulated strain of GBS was injected into the cerebral ventricle. There were minimal inflammatory changes to bacterial doses of $10^{6}$ and $10^{7} \mathrm{CFU}$ equivalents. With higher bacterial doses $\left(10^{8}-10^{9}\right.$ CFU equivalents), there was a modest increase in TNF and 6-keto-PGF ${ }_{1 \alpha}$ levels. When compared with the response to the unencapsulated strain (Fig. 3), the response was of a much lesser magnitude and peaked later (4-6 h).

\section{DISCUSSION}

In the past few years, animal models of meningitis have added to the understanding of the pathophysiology of bacterial meningitis, including the role of bacterial components initiat- ing the inflammatory response, the participation of chemical mediators, the role of polymorphonuclear neutrophils, and the altered physiology in the brain (4-7). Both the bacterial cell wall and the capsule are involved in the virulence of Grampositive bacteria. The polysaccharide capsule is thought to contribute to the bacterial invasiveness by facilitating their evasion of host recognition, but has no direct role in inflammation. Using a pneumococcal meningitis model, Tuomanen $e$ al. (9) reported that CSF inflammatory changes could be induced by cisternal instillation of $10^{5}-10^{6}$ cell equivalents of whole, heat-killed unencapsulated strains or their isolated cell walls, but not by similar concentrations of heat-killed encapsulated strains or isolated capsular polysaccharide. They con- 
cluded that the cell wall was responsible for the induction of inflammation. Täuber et al. (10) demonstrated that the pneumococcal cell wall not only induced cytochemical changes in the CSF, but also pathophysiologic alterations in the brain (brain edema and increased intracranial pressure) similar to true bacterial meningitis.

Most previous studies of bacterial meningitis used adult rabbit or rat models, with direct intracisternal inoculation of bacteria, such as Streptococcus pneumoniae, Neisseria meningitidis, Escherichia coli, and Haemophilus influenzae. In view of the developmental immaturity of the CNS and immature defense mechanism in the newborn, the development of a newborn experimental meningitis model would facilitate the study of the pathophysiology of neonatal meningitis and the mechanism for brain damage. We chose to use a newborn piglet model using GBS. Previous publications have validated newborn piglets as an appropriate animal model for the study of cerebral blood flow and the biochemical control of cerebral blood flow in newborn animals $(17,18)$. GBS is a common etiologic agent in causing neonatal sepsis and, type III in particular, in causing neonatal meningitis (8). A mutant unencapsulated strain of type III GBS was heat-killed to provide as a source of exposed cell wall. In true bacterial meningitis, the bacteria multiply in the $\mathrm{CSF}$, and once the concentration reaches a critical level $\left(10^{5}-10^{6} \mathrm{CFU} / \mathrm{mL}\right)$, the inflammatory cascade is initiated. Therefore, we chose a large bacterial dose $\left(10^{9} \mathrm{CFU}\right.$ equivalents in $0.5 \mathrm{~mL}$ ) for the first part of the study. This would mimic the concentration of bacterial products in the CSF in a fulminant case of bacterial meningitis or during treatment with bacteriolytic antibiotics resulting in a rapid and massive release of bacterial products. Intraventricular route of inoculation was chosen because the choroid plexus had been suggested to be the first site of inflammation in bacterial meningitis (19).

Similar to Tuomanen's previous observations with $S$. pneumoniae (9), we found that the heat-killed unencapsulated GBS with exposed cell wall is capable of inducing meningeal inflammation with a marked increase of leukocytes, protein, TNF, and PG, evident by $6 \mathrm{~h}$. The increase in TNF and PG concentrations showed a positive relationship with the bacterial dose: the higher bacterial doses were associated with a greater magnitude of increase and also an earlier peak, as illustrated by TNF and 6-keto-PGF ${ }_{1 \alpha}$ in Figure 3. These findings strongly suggest that the cell wall is likely the active bacterial component causing inflammation, and the capsule is not necessary for the inflammatory response. The encapsulated strain caused only minimal inflammatory changes except at very high doses, suggesting that the presence of the capsule may "shield" the inflammatory potential of the underlying cell wall. At high doses $\left(10^{8}\right.$ or above), the encapsulated strain did produce a modest increase in inflammatory markers. It is possible that, over the time course of the experiment, the underlying cell wall could become accessible to host defense, thereby initiating inflammation. These findings are similar to those of Tuomanen et al. (9). Using S. pneumoniae in an adult rabbit mode, they demonstrated that CSF inflammatory changes could be induced by similar concentrations of different strains of live bacteria (encapsulated and unencapsulated), and similar cell equiva- lents of whole, heat-killed unencapsulated strains, but not by similar concentrations of heat-killed encapsulated strains. Because the heat-killed unencapsulated bacteria can produce qualitatively and quantitatively similar CSF responses to that of the live bacteria in true infections $(9,10)$, we propose that it can be used to induce experimental meningitis.

The time course of the meningeal inflammation showed that TNF increased briskly, by several hundredfold, with a peak preceding those of CSF leukocytosis and protein. This suggests the pivotal role of TNF as a cytokine responsible for initiating the inflammatory cascade and is followed by other inflammatory mediators, including PG, which peaked later than TNF. This is in agreement with other experimental models of meningitis (4-7) where it has been shown that cytokines (TNF and IL-1) induce phospholipase $\mathrm{A}_{2}$ activity and trigger the production of $\mathrm{PG}$, platelet-activating factor, and leukotriene $\mathrm{B}_{4}$. Other investigators had previously documented increased PG concentration in CSF in human and experimental meningitis and demonstrated reduction in injury with the use of PG synthetase inhibitors $(20-23)$. The inflammatory mediators showed a brisk rise as well as a brisk fall, returning to almost baseline by $6 \mathrm{~h}$. The leukocytosis and protein levels did not increase until $6 \mathrm{~h}$, and once inflammation was established, both were still very elevated at $24 \mathrm{~h}$.

In summary, neonatal piglets given intraventricular heatkilled GBS with exposed cell wall is a valid model for neonatal meningitis. This model has two potential advantages over the use of live bacteria. The effect of meningitis on the brain can be studied without the confounding systemic complications of a true GBS sepsis, such as hypotension, which may by itself compromise cerebral blood flow. Second, the time course of events is well defined as it does not require bacterial multiplication for initiation of inflammation. The effects of inflammatory cytokines on the blood-brain barrier and intracranial pressure have been described (4-7). The loss of autoregulation and the association of brain edema with increased PG concentrations have been reported in experimental meningitis $(24,25)$. $\mathrm{PGE}_{2}, \mathrm{PGF}_{2 \alpha}, \mathrm{PGI}_{2}$, and $\mathrm{TXA}_{2}$ are known to have major vasoactive properties and may play a prominent role in the cerebral blood flow control in the newborn CNS. This model can be used to study the pathophysiology of inflammation on the CNS, and the mechanisms for brain damage in neonatal meningitis.

Acknowledgment. The authors thank Genentech Inc. for providing the TNF ELISA kits.

\section{REFERENCES}

1. Shattuck KE, Chonmaitree T 1992 The changing spectrum of neonatal meningitis over a fifteen-year period. Clin Pediatr 31:130-136

2. Klein JO, Marcy SM 1995 Bacterial sepsis and meningitis. In: Remington JS, Klein JO (eds) Infectious Diseases of the Fetus and Newborn Infants. Fourth edition. WB Saunders, Philadelphia, pp 835-890

3. Hristeva L, Booy R, Bowler I, Wilkinson AR 1993 Prospective surveillance of neonatal meningitis. Arch Dis Child 69:14-18

4. Sande MA, Tauber MG, Scheld MD, McCracken Jr GH, and the Meningitis Study Group 1989 Report of a second workshop: pathophysiology of bacterial meningitis. Pediatr Infect Dis J 8:901-933

5. Saez-Llorens X, Ramilo O, Mustafa MM, Mertsola J, McCracken Jr GH 1990 Molecular pathophysiology of bacterial meningitis: current concepts and therapeutic implications. J Pediatr 1 16:671-684 
6. Tunkel AR, Wispelwey B, Scheld WM 1990 Bacterial meningitis: recent advances in pathophysiology and treatment. Ann Intern Med 112:610-623

7. Quagliarello V, Scheld WM 1992 Bacterial meningitis: pathogenesis, pathophysiology and progress. N Engl J Med 327:864-872

8. Baker CJ, Edwards MS 1995 Group B streptococcal infections. In: Remington JS, Klein JO (eds) Infectious Diseases of the Fetus and Newborn Infants, Ed. 4. WB Saunders, Philadelphia, pp 980-1028

9. Tuomanen E, Tomasz A, Hengstler B 1985 The relative role of bacterial wall and capsule in the induction of inflammation in pneumococcal meningitis. J Infect Dis 151:535-40

10. Täuber $M G$, Burroughs $M$, Niemoller UM, Kuster $H$, Borschberg $U$, Tuomanen $E$ 1991 Differences of pathophysiology in experimental meningitis caused by three strains of streptococcal pneumoniae. J Infect Dis 163:806-811

11. McKnight AA, Keyes WG, Hudak ML, Jones Jr MD 1992 Oxygen free radicals and the cerebral arteriolar response to group B streptococci. Pediatr Res 31:640-644

12. Laudignon N, Beharry K, Rex J, Aranda JV 1990 Effect of adenosine on total and regional blood flow of the newborn piglet. J Cereb Blood Flow Metab 10:392-398

13. Rubens CE, Heggen LM, Haft RF, Wessels MR 1993 Identification of cpsD, a gen essential for type III capsule expression in group B streptococcus. Mol Microbiol 8:843-855

14. Martin TR, Rubens CE, Wilson CB 1988 Lung antibacterial defense mechanisms in infant and adult rats: implications for the pathogenesis of group B streptococcal infections in the neonatal lung. J Infect Dis 157:91-100

15. Gibson RL, Truog WE, Henderson WR, Jr., Redding GJ 1992 Group B streptococcal sepsis in piglets: effect of combined pentoxifylline and indomethacin pretreatment. Pediatr Res 321:222-227

16. Gibson RL, Redding GJ, Henderson WR, Truog WE 1991 Group B streptococcus induces tumor necrosis factor in neonatal piglets (effect of the tumor necrosis factor inhibitor pentoxifylline on hemodynamics and gas exchange. Am Rev Respir Dis 143:598-604

17. Chemtob S, Laudignon N, Beharry K, Rex J, Varma D, Wolfe L, Aranda JV 1990 Effects of prostaglandins and indomethacin on cerebral blood flow and cerebral oxygen consumption of conscious newborn piglets. Dev Pharmacol Ther 14:1-14

18. Chemtob S, Beharry K, Rex J, Varma DR, Aranda JV 1990 Prostanoids determine the range of cerebral blood flow autoregulation of newborn piglets. Stroke 21:777-784

19. Smith AL, Daum RS, Scheifele D 1982 Pathogenesis of Haemophilus influenzae. In: Sell SH, Wright PF (eds) Haemophilus influenzae: Epidemiology, Immunology, and Prevention of Disease. Elsevier Science Publishing, New York, pp 89-109

20. Tuomanen E, Hengstler B, Roland R, Bray MA, Zak O, Tomasz A 1987 Nonsteroida anti-inflammatory agents in the therapy for experimental pneumococcal meningitis. J Infect Dis 155:985-990

21. Kadurugamuwa JL, Hengstler B, Zak O 1989 Cerebrospinal fluid protein profile in experimental pneumococcal meningitis and its alteration by ampicillin and antiinflammatory agents. J Infect Dis 159:26-34

22. Mustafa MM, Ramilo O, Saez-Llorens X, Mertsola J, Magness RR. McCracken GH Jr 1989 Prostaglandins E2 and I2, interleukin $1 \beta$, and tumor necrosis factor in cerebrospinal fluid in infants and children with bacterial meningitis. Pediatr Infect Dis J 8:921-922

23. Tureen JH, Täuber MG, Sande MA 1991 Effects of indomethacin on the pathophysiology of experimental meningitis in rabbits. J Infect Dis 163:647-649

24. Smith AL, Scheifele D, Daum R., Averill D, Syriopolou V 1987 Cerebral blood flow in experimental Haemophilus influenzae b meningitis. Pediatr Infect Dis J 6:1159

25. Tureen JH, Dworkin RJ, Kennedy SL, Sachdeva M, Sande MA 1990 Loss of cerebrovascular autoregulation in experimental meningitis in rabbits. $J$ Clin Invest $85: 577-581$ 